\title{
Incidental or Intentional Learning? Two Compatible Processes
}

\author{
Pablo Camacho* \\ Doctor in Physical Activity and Sports Sciences, Pablo de Olavide University, Spain
}

Submission: March 09, 2018; Published: March20, 2018

*Corresponding author: Pablo Camacho, Doctor in Physical Activity and Sports Sciences, Pablo de Olavide University, Spain; Email: pcamacholazarraga@gmail.com

\section{Abstract}

In some sports players must select the relevant information to conveniently decide between several options, such as football, basketball, soccer, etc. In addition, these decisions are generally linked to situations of high pressure, little time and information available. These are situations where it is not possible to make a conscious selection of all the information, as well as possible solutions. The choice of this may mean success or failure. Because deliberate strategies require consecutive processing and focus attention on particular information, and its main limitation is that the subject's short-term memory capacity is limited, the amount of information that can be handled by this type processing is low. Research shows that incidental learning outperforms intentional learning in some characteristics, or simply that movements can be learned implicitly. However, we must study the relative contribution of both processes. That is why we can say that a truly right decision will be based on a balance between deliberate and instinctive thinking.

\section{Introduction}

Our daily life is full of numerous examples that reveal how much of our behavior and our knowledge comes from unconscious learning, that is, behaviors and knowledge learned without intending to learn them, without having been aware of having learned them and about which even currently we may not be aware of having acquired them [1]. It is at the end of the 1980s that a line of research focused on distinguishing between two types of learning acquires force: intentional or selective and incidental or non-selective [2]. Since Arthur Reber referred to this last type of learning as "incidental learning" in 1967, twenty years have gone by in which there has been no concern for this concept, and twenty years in which there has been growing interest in its existence. When we want to find the differences between incidental and intentional learning, it is common to observe definitions that relate these two forms of learning to two different processes: conscious processing and non-conscious processing of information [3].

In the field of cognitive psychology, the term "incidental" refers to unconscious phenomena, and figures as opposed to the term "intentional", used to refer to conscious processes. In the framework of learning, we conceive incidental learning as the acquisition of knowledge without awareness of having learned it. However, most attempts to define this phenomenon coincide in conceiving it in a broader way, highlighting not only the unconscious nature of learning, but also the absence of intention to learn [1]. As stated by Raab, Johnson [4], incidental learning occurs in situations in which there has been no intention to learn or explicit knowledge about the structure of the rule underlying that situation. In contrast, we understand intentional learning when the subject has the intention to learn, and for this he uses conscious strategies that result in knowledge accessible to the conscience.

In some situations we are aware of the learning we do, of the course of thought that leads us to make certain decisions, we can describe it through some kind of logical structure and, consequently, the decisions are accompanied by an easily verbalizable knowledge. On the contrary, in other situations our decisions seem to be based on intuition. We cannot explain the reasons that have led us to make a certain decision, and therefore the knowledge resulting from this type of learning is considered incidental and non-verbalizable [3].

That is why we say that learning is incidental if it meets two conditions: learning unintentionally and doing it without awareness of having learned it. On the contrary, learning will be explicit when the learning has been done intentionally and also can be verbalized. Therefore, we will define the process of incidental learning as an unintentional and automatic acquisition of knowledge about the structural relationships between objects or events [5], and intentional learning when using instructions that identify relationships in the task or the objectives of the learning process [6]. Each of these processes will lead to improvements in behavior.

\section{Deliberative and Instintive Processes}

Froufe [7] synthesizes the analysis of numerous researchers on the differences between incidental and intentional processing. 
The main problem lies in the role attributed to consciousness, understood as the boundary between the intentional and the incidental. The problem we must solve is whether there can be learning without being aware of having established new relationships capable of producing changes in decisions at the conscious level.

\section{Deliberative Processing}

We use the term intentional when the subject makes a conscious effort to recover the information that has been presented previously [8]. Although it has been accepted that consciousness plays an important role in some learning processes, in the field of learning and motor development its importance in the control of the action has been questioned. "The awareness of the intention precedes the movement, but the potentials of preparation in turn precede the conscious intention to perform the action". So, if the brain was already preparing the action before realizing its intention to act. To do so, what role does consciousness play in that continuum? "Gray proposed an intriguing response that gives conscience the role of supervisor of results. The functional value of consciousness would not be to control the deployment of the action, but rather that of detecting discrepancies between the global plans and their results, in this sense, the direction of the action would be a consequence of nonconscious processes, and the conscience would play a role as an ex post facto evaluator of the result".

In some sports players must select the relevant information to conveniently decide between several options, such as football, basketball, soccer, etc. In addition, these decisions are generally linked to situations of high pressure, little time and information available [9]. These are situations where it is not possible to make a conscious selection of all the information, as well as possible solutions. The choice of this may mean success or failure [10].

Because deliberate strategies require consecutive processing and focus attention on particular information, and its main limitation is that the subject's short-term memory capacity is limited, the amount of information that can be handled by this type processing is low [11]. An internal chaos would occur if the subject were aware at all times of all the information of their environment, due to their inability to act and the difficulty in responding to external and internal stimulation [12]. On the other hand, it seems that in incidental or automatic processing information is treated in a parallel way, considering multiple information simultaneously [11].

\section{Intuitive or Incidental Processing}

In team sports, athletes often report that in certain situations under pressure of time their actions take place without any conscious control, without being able to give more details of the reasons that lead to it, attributing it to intuition [13]. Hogarth [14] argues that intuitive decisions in sports can be considered as the result of rapid processing stimuli through a tacit system independent of any physiological feeling. Within the sport context, when we speak of incidental learning, we must make a distinction between incidental motor learning, that is, how we produce a specific movement, and incidental cognitive learning, that is, how we construct judgments about the relationship between stimuli and actions that must be carried out [15].

Martínez [1] states that incidental learning is the product of automatic associative processes that operate independently of the cognitive load, associating only those elements that are kept simultaneously in the working memory. The entrance to this process is mainly provided by the knowledge stored in the longterm memory, acquired mainly through associative learning. The entrance is treated automatically, without conscious knowledge. The result of the process is a feeling that can serve as a basis for judgments and decision making [11].

We conceive intuition as a function of psychological synthesis, since in order to make a decision we capture the totality of a given situation, synthesizing isolated bits of data and experiences related to the demands of each situation [16]. Some authors argue that intuitive decisions are the result of the phenomenological awareness of some discriminative and internal physiological states that evolve from non-conscious processing stimuli [17].

All kinds of innate processes, such as reflexes and instinctive behavior models, are not considered intuitive, because they do not need prior knowledge stored in long-term memory [11]. The knowledge base of intuition seems to be incidental knowledge, while deliberation would be based on explicit knowledge [18]. But, to what extent is incidental learning the basis of intuitive processing? Plessner, Czenna [19] indicate that incidental learning will most likely produce intuitive decisions, while the characteristics of intentional learning will tend to initiate deliberate decision making. But we must indicate that intuition may not only be the result of incidental learning, but may also be learned explicitly, and become automatic with experience.

To know if the learning acquired in any procedure or task has been unconscious, the ideal evaluation should track the three internal areas of learning (acquisition process, content represented in memory, and expression of what has been learned). The method generally used has been the search for dissociation between what have come to be called direct measures and indirect measures of learning. The direct measures would be those in which the participant is specifically asked to try to remember what they have learned; therefore they are measures that induce the conscious use of relevant knowledge. On the other hand, indirect measures would be those that allow observation of learning without asking the participant to reveal what has been learned, thus avoiding promoting the use of conscious knowledge [1].

This same author tells us that the search for evidence of unconscious learning has been carried out through three fundamental tasks, artificial grammars, complex systems, and sequence learning. Execution in artificial grammars seems to reflect both conscious and unconscious processes, and it 
is difficult to know to what extent they influence each other. With regard to the task of controlling complex systems, for the moment the intentional character of learning cannot be ruled out and the thoroughness of the measures of conscience used is questionable. In contrast, the third of the described paradigms, sequence learning, presents three variants (fixed sequence, fixed multiple sequences and probabilistic sequences) that until now are offering the best evidence of incidental learning with objective measures of consciousness. Therefore, sequence learning has become the most effective experimental task to study incidental learning [20].

Within the area of implicit cognition there are three main lines of research: Implicit Perception (IP), Implicit Memory (IM), and Incidental Learning (IA) [21]. According to Froufe [7], IP is the product of the codification of events that go unnoticed to conscious processing but that do not imply the formation of a representation in the mind. IM involves the organization of the implicit perceptions in an internal non-conscious mental representation, that is, in a storage format proper to the mind. According to Cañas et al. [8] is a situation where the recovery of information is not done with conscious effort. The experimental subject is presented with known information, and in the recovery phase is not asked to remember that information. Instead, you are asked to perform a task in which you will have better execution if you retrieve the information presented previously. And finally the IA, which is the product of the acquisition and subsequent non-conscious transfer of regularities between the stimuli learned and that have already been represented in the IM. Therefore, the IA will be defined as the mental process that occurs from the acquisition and transfer of patterns in the absence of a phenomenological knowledge.

\section{Results of the Studies Carried Out}

There have been some studies that try to prove that intuitive decision-making can be successful, at least, as well as more deliberate strategies. In this attempt, the investigations referring to both types of learning have been directed towards checking the following points:

a. The resistance to time.

b. Efficiency of the double process of motor control and decision making.

c. The effectiveness in making decisions with a time limit.

d. The effectiveness in situations of different complexity.

Regarding the first point, resistance to time, understanding this as solidity before oblivion, some studies have shown that implicit memory is more durable and resistant to the passage of time than explicit memory [5]. For his part, Raab [5] also states that in his studies he has found clear evidence that when performing retention tests, after four weeks there has not been a significant decrease in the quality of the decision making, which proves the solidity of incidental learning.
In relation to the second point, effectiveness of the double decision-making process and motor control, there are also indications that incidental learning is more advantageous than intentional learning. Studies such as those carried out by Masters et al. [22] and Poolton et al. [23] confirm this, demonstrating that in situations where time is too short for decision-making and in addition a response is needed immediate motor, the effectiveness of incidental processing allows a better performance. Regarding the third point, the effectiveness in making decisions with a time limit, Masters et al. [22] indicates that incidental processes are faster and organized as sophisticated knowledge that can be applied without awareness. They are therefore independent of working memory, which leaves the player with sufficient resources to perform other tasks, such as making decisions.

Regarding the fourth and last point, the effectiveness in situations of different complexity, the results obtained by the different investigations carried out also reach the conclusion that incidental learning confers greater benefits than intentional learning [24]. Research shows that incidental learning outperforms intentional learning in some characteristics [25], or simply that movements can be learned implicitly. As stated by Raab, Johnson [4].

\section{Two Compatible Processing}

In competitive sport, the variables speed and accuracy play an important role, both in terms of information processing, decision making and motor execution [26]. Currently, studies in the field of neuroscience have shown that the human being is endowed with phylogenetic mechanisms that help him to process information both consciously (when there is time) and unconscious (when time is at a minimum) [27]. It has been gaining recognition that it is difficult to find a situation in which a single type of learning is developed [28]. As Betsch [11] points out, automatic processes and deliberate processes work simultaneously, and therefore as a whole they form thought and action.

Raab, Johnson [4] argue that when one speaks of intuitive and deliberate decision-making, it does not necessarily mean that the protocol is performed completely intuitively or deliberately. Both processes will be poles of a continuous series. That is, decisions may be more or less intuitive or more or less deliberate. Raab [5] states that both processes are adaptable to environmental changes, and that the complexity of situations will serve as a crucial factor in understanding the advantage of having two adaptive systems. Sun et al. [28] advocate an integrated learning model that takes into account both incidental processes and intentional processes, arguing that both types of processes and knowledge coexist and interact with each other to form learning and performance.

In short, as Iglesias et al. [27], we need to develop two types of cognitive mechanisms: those that allow to make reasoned decisions, because there is enough time (although it is always reduced in basketball) to make the decision, and those that 
make the most intuitive decisions possible, without intervenes consciousness. For both, the slogans regarding the design of the task will be similar. What should change is the intervention of the coach: in some cases they will be helped to reflect on what they do and what they should do, and in others the subject will be expected to explore and look for answers freely. When it comes to distinguishing the different thinking strategies on the empirical level, we must study the relative contribution of both processes [18]. That is why we can say that a truly right decision will be based on a balance between deliberate and instinctive thinking [29,30]. What are the factors or situations that determine whether intuitive or deliberative processing is the most successful? It will therefore be very important to consider what factors determine whether a given situation will be treated more deliberately or more intuitively. The internal logic of the designed task will provide the means to execute strategies to a greater or lesser degree incidental or intentional.

\section{References}

1. Martínez JM (2004) Aprendizaje implícito y explícito de secuencias: determinantes e indicadores. Universidad de Granada pp. 179.

2. Berry DC, Broadment DE (1988) Interactive tasks and the implicit explicit distinction. British Journal of Psychology 79(2): 251-272.

3. Tubau E, Moliner J (1999) Aprendizaje implícito y explícito: dos procesos diferentes o dos niveles de abstracción? Anuario de Psicología 1(30): 3-23.

4. Raab M, Johnson J (2008) Implicit learning as a means to intuitive decision making in sports. $\mathrm{H}$ Plessner, $\mathrm{C}$ Betsch, T Betsch (Eds.), Intuition in judgment and decision making. Lawrence Erlbaum Associates, New York, USA, pp. 119-133.

5. Raab M (2003) Decision making in sports: influence of complexity on implicit and explicit learning. Journal of Sport and Exercise 1(4): 310337.

6. Reber A (1989) Implicit learning and tacit knowledge. Journal of Experimental Psychology 118: 219-235.

7. Froufe M (1997) El inconsciente cognitivo: La cara oculta de la mente. Biblioteca Nueva, Madrid, Spain.

8. Cañas JJ, Quesada JF, Antolí A (1999) Flexibilidad del conocimiento implícito. Psicothema 11(4): 901-916.

9. Gigerenzer G, Todd PM (1999) Simple heuristics that make us smart. Oxford University Press, UK.

10. Bennis W, Pachur $T$ (2006) Fast and frugal heuristics in sports Psychology of Sport and Exercise 7(6): 611-629.

11. Betsch $\mathrm{T}$ (2008a) The nature of intuition and its Neglect in research on judgment and decision making. In H Plessner, C Betsch, T Betsch (Eds.), Intuition in judgment and decision making. Lawrence Erlbaum Associates, New York, USA, pp. 3-22.

12. Núñez JP (1998) Aprendizaje inconsciente. Condicionamiento a estímulos visuales subliminales. Universidad de Madrid, Spain, pp. 375.

13. Kibele A (2006) Non-consciously controlled decision making for fast motor reactions in sports: A priming approach for motor responses to non- consciously perceived movement features. Psychology of Sport and Exercise 7(6): 591-610.

14. Hogarth RM (2001) Educating intuition. The University of Chicago Press, Chicago, USA.

15. Masters RSW, Law J, Maxwell J (2002) Implicit and explicit learning in interceptive actions. In K Davids, G Savelsbergh, J van der Kamp (Eds.), Interceptive actions in sport: Information and movement. Routledge, London, pp. 126-143.

16. Khatri $\mathrm{N}, \mathrm{Ng} \mathrm{AH}(2000)$ The role of intuition in strategic decision making. Human relations 53(1): 57-86.

17. Perrig WJ, Wippich W (1995) Intuition in the context of perception, memory and judgement. In B Boothe, R Hirsig, A Helminger, B Meier, R Volkart (Eds.), Perception-evaluation-interpretation. Swiss Monographs in Psychology 3: 21-31.

18. Betsch C (2008b) Chronic preferences for intuition and deliberation in decision making lessons learned about intuition from an individual differences approach. In H Plessner, C Betsch, T Betsch (Eds.), Intuition in judgment and decision making. Lawrence Erlbaum Associates, New York, USA, pp. 231-248.

19. Plessner H, Czenna S (2008) The benefits of intuition. En H Plessner, C Betsch, T Betsch (Eds.), Intuition in judgment and decision making. Lawrence Erlbaum Associates, New York, USA, pp. 251-265.

20. Destrebecqz A, Cleeremans A (2001) Can sequence learning be implicit? New evidence with the process dissociation procedure. Psychonomic Bulletin and Review 8(2): 343-350.

21. López MF, Introzzi I, Richard's MM (2009) La independencia del aprendizaje implícito con respecto a la inteligencia general en niños de edad escolar. Anales de Psicología 25 (1): 112-122.

22. Masters R, Poolton J, Maxwell J, Raab M (2008) Implicit motor learning and complex decision making in time-constrained environments. Journal of Motor Behavior 40(1): 71-79.

23. Poolton JM, Masters RS, Maxwell JP (2006) The influence of analogy learning on decision-making in table tennis: Evidence from behavioural data. Psychology of Sport and Exercise 7(6): 677-688.

24. Johnstone T, Shanks D (2001) Abstractionist and processing accounts of implicit learning. Cognitive Psychology 42(1): 61-112.

25. Poolton J, Zachry T (2007) So you want to learn implicitly? Coaching and learning through implicit motor learning techniques. International Journal of Sports Science y Coaching 2(1): 67-78.

26. Ezquerro M, Buceta JM (2001) Estilo de procesamiento de la información y toma de decisiones en competiciones deportivas: Las dimensiones rapidez y exactitud cognitivas. Análise Psicológica 19(1): 37-50.

27. Iglesias D, Cárdenas D, Alarcón F (2007) La comunicación durante la intervención didáctica del entrenador. Consideraciones para el desarrollo del conocimiento táctico y la mejora en la toma de decisiones en baloncesto. Ciencia, Cultura Deporte 3 (7): 43-50.

28. Sun R, Slusarz P, Terry C (2005) The interaction of the explicit and the implicit in skill learning: A dual-process approach. Psychological Review 112(1): 159-192.

29. Gladwell M (2005) Inteligencia intuitiva: Por qué sabemos la verdad en dos segundos? Taurus, Madrid, Spain, pp. 304.

30. Libet B (1985) Unconscious cerebral initiative and the role of conscious will in voluntary action. Behavioral and Brain Sciences 8(4): 529-566. 
CC (i) This work is licensed under Creative (C) Commons Attribution 4.0 License

BY DOI: 10.19080/JPFMTS.2018.02.555587
Your next submission with Juniper Publishers will reach you the below assets

- Quality Editorial service

- Swift Peer Review

- Reprints availability

- E-prints Service

- Manuscript Podcast for convenient understanding

- Global attainment for your research

- Manuscript accessibility in different formats ( Pdf, E-pub, Full Text, Audio)

- Unceasing customer service

Track the below URL for one-step submission https://juniperpublishers.com/online-submission.php 